\title{
INVITATION \\ to the 4th ASTIN Colloquium
}

As you have probably noted from Vol. II, Part II, of the ASTIN Bulletin, arrangements are being made for the fourth ASTIN Colloquium to be held in Trieste from Igth to 2Ist September I963.

The Colloquium is being organised by the Italian Institute of Actuaries and will follow the successful pattern of the earlier meetings. Two topics have been proposed for discussion, namely the Theory of Extreme Values and the Actuarial Control of NonLife Accounts.

The first topic follows up the discussions initiated at Juan-lesPins; members present will recall among others the paper by Professor Franckx and the subsequent discussions. Recently our Chairman, R. E. Beard, had the opportunity of giving some talks to the Scandinavian Actuarial Societies and some notes based on these are attached. It is hoped these will be useful to members in preparing papers for discussion at the Colloquium. It is proposed to devote the first day to this subject.

The second subject, Actuarial Control, extends over a very wide field of practical importance and it is proposed to devote the remaining two days to this subject: three sessions devoted to Claims, Unexpired Risks Reserve and Contingency and Other Reserves respectively, and a final session covering general matters. Some notes on the subject are also attached which might also be found useful to provoking discussion.

Members who are likely to be able to attend are invited to write before 3 Ist March 1963 to:

$$
\begin{gathered}
\text { Istituto Italiano degli Attuari, } \\
\text { 66, Via dell'Arancio, } \\
\text { Rome, }
\end{gathered}
$$

indicating whether they will be sending in written contributions, 
of which roo copies should be sent by zoth June I963 so that they can be in the hands of participants in good time before the meeting. They should also indicate whether they are likely to be accompanied.

As is customary, the languages of the Colloquium will be English and French and papers may be submitted in either language.

Full details regarding registration and other formalities will be sent in due course to all members signifying their intention to attend. 